\title{
Práticas de racismo e xenofobia contra universitários caribenhos em Belém do Pará. ${ }^{1}$
}

\author{
Prácticas de racismo y xenofobia contra universitarios caribeños en Belém \\ do Pará.
}
Practices of racism and xenophobia against Caribbean university students in Belém do Pará.

\author{
Felipe Carlos Damasceno e Silva ${ }^{2}$ \\ Marilu Marcia Campelo ${ }^{3}$
}

\begin{abstract}
Resumo
Este trabalho nasceu a partir da produção de uma pesquisa de iniciação científica na qual se pode verificar, através do processo reflexivo, a demanda de investigar mais a fundo as relações cotidianas do/as interlocutores/as participantes. A princípio, se pretendia pesquisar sobre as relações de gênero existentes entre universitários/as haitianos/as no contexto da cidade de Belém do Pará. No entanto, através das primeiras entrevistas semiestruturadas realizadas no âmbito da referida pesquisa, foram identificados relatos de racismo e xenofobia sofridos pelos/as já mencionados/as estudantes. Diante do exposto se julgou pertinente alterar as categorias analíticas da pesquisa, estendê-la a uma monografia de conclusão da graduação em Ciências Sociais pela Universidade Federal do Pará, e, além de haitianos/as, expandir os/as sujeitos/as pesquisados/as para universitários/as oriundos/as dos demais países caribenhos. Esta pesquisa está dividida em três partes. Na primeira parte apresento um levantamento bibliográfico acerca da literatura sobre racismo e xenofobia buscando sinalizar as contribuições mais importantes sobre estas categorias em distintos contextos geográficos. Na segunda parte, ao realizar entrevistas semiestruturadas, busco identificar práticas de racismo e xenofobia no diaa- dia de universitários/as oriundos/as de países caribenhos em Belém do Pará, e em seguida analisar seus impactos. Ao finalizar, faz-se um debate visando instigar novas pesquisas que contribuam para a luta antirracista.
\end{abstract}

Palavras-Chave: Racismo; Xenofobia; Universitários; Caribenhos.

\section{Resumen}

Este trabajo nació a partir de la producción de una investigación de iniciación científica en el cual se puede verificar, a través del proceso reflexivo, la demanda de investigar más a fondo las relaciones cotidianas delos/as interlocutores/as participantes. En principio, se pretendía investigar sobre las relaciones de género existente entre universitarios/as haitianos/as en el contexto de la ciudad de Belém do Pará. Sin embargo, a través de las primeras entrevistas semiestructuradas realizadas en el ámbito de la referida investigación, se identificaron relatos de racismo y xenofobia sufridos por los ya mencionados/a los estudiantes. En el caso de que se produzca un cambio en las categorías analíticas de la investigación, extenderla a una monografía de conclusión de la graduación en Ciencias Sociales por la Universidad Federal de Pará, y, además de haitianos/as, expandir los/as sujetos/as encuestados/as para universitarios/as oriundos/as de los demás países caribeños. Esta investigación está dividida en tres partes. En la primera parte presento un levantamiento bibliográfico acerca de la literatura sobre racismo y xenofobia buscando señalar las contribuciones más importantes sobre estas categorías en distintos contextos

\footnotetext{
${ }^{1}$ Artigo apresentado no Simpósio Temático: 'Jovens pesquisadores Latino-americanos”' durante o II Seminário Latino-Americano de Estudos em Cultura - SEMLACult em Foz do Iguaçu/PR, Brasil, 2018.
}

2 (Graduado em Ciências sociais, Universidade Federal do Pará; Belém, Pará, Brasil; felipedamasceno33@gmail.com).

3 (Doutora em Antropologia, Docente, Universidade Federal do Pará; Belém, Pará, Brasil; dodoyaster@gmail.com). 
geográficos. En la segunda parte, al realizar entrevistas semiestructuradas, busco identificar prácticas de racismo y xenofobia en el día a día de universitarios/as oriundos/as de países caribeños en Belém do Pará, luego analizar sus impactos. Al finalizar, se hace un debate para instigar nuevas investigaciones que contribuyan a la lucha antirracista.

Palabras clave: Racismo; Xenofobia; Universitários; Caribeños.

\begin{abstract}
This work was born from the production of a research of scientific initiation in which one can verify, through the reflexive process, the demand to investigate more in depth the daily relations of the participant participants. At first, it was intended to investigate the existing gender relations among Haitian university students in the context of the city of Belém do Pará. However, through the first semi-structured interviews carried out within this research, reports of racism and xenophobia suffered by those already mentioned / the students. In view of the above, it was considered relevant to change the analytical categories of the research, to extend it to a monograph of conclusion of the graduation in Social Sciences by the Federal University of Pará, and in addition to Haitians, to expand the researched subjects for university students from other Caribbean countries. This research is divided into three parts. In the first part I present a bibliographical survey about the literature on racism and xenophobia, seeking to signal the most important contributions about these categories in different geographic contexts. In the second part, when conducting semi-structured interviews, I try to identify practices of racism and xenophobia in the daily life of university students from Caribbean countries in Belém do Pará, and then analyze their impacts. At the end, there is a debate aimed at instigating new research that contributes to the anti-racist struggle.
\end{abstract}

Keywords: Racism; Xenophobia; College students; Caribbean people.

\title{
1. Introdução
}

Esta pesquisa surgiu com objetivo de investigar o caráter relacional de gênero nas relações de estudantes caribenhos com brasileiros e brasileiras em suas vivências na Cidade de Belém do Pará, porém, em todas as entrevistas semiestruturadas (DUARTE, 2002, p, 147) realizadas foram identificados relatos de racismo e xenofobia praticados contra os/as interlocutores/as participantes, e diante de tal problemática, julgou-se pertinente alterar as bases analíticas da pesquisa objetivando problematizar as referidas práticas no cotidiano deste grupo de estudantes, à luz da teoria antropológica e de alguns estudos sobre racismo e xenofobia.

De acordo com Munanga (2004, p, 01) 'O conceito etimológico de raça 'veio do italiano razza, que por sua vez veio do latim ratio, que significa sorte, categoria, espécie'. E a partir dela, surgiu um comportamento chamado racismo (BANTON, 1977, p. 39). Já a palavra xenofobia vem do grego, através da junção das palavras xénos que significa: estranho ou estrangeiro com a palavra phobos que significa: medo. Logo, xenofobia é o termo utilizado para definir medo, rejeição, aversão, etc. ao estrangeiro (DE ALBUQUERQUE JR, 2016, p.09).

Trata-se de uma pesquisa qualitativa de caráter preliminar e exploratório com proposta investigativa baseada em entrevistas semiestruturadas temáticas, como perspectiva metodológica de compreensão do problema. O nosso propósito foi realizar tais entrevistas 
privilegiando aspectos das experiências migratórias relacionadas às formas e espaços de sociabilidade no lazer, na Universidade, no trabalho, associações, na vizinhança, estilos de vida, organização do cotidiano e trajetória familiar de cada um de nossos/as entrevistados/as (PISCITELLI, 1993). Nesse sentido, seguem abaixo alguns resultados da obtidos pela referida pesquisa.

\section{Apontamentos sobre o racismo}

Antes de adentrarmos na questão no racismo no Brasil, julgamos relevante trazer ao nosso debate um brevíssimo histórico da gênese do racismo em caráter histórico e mundial. Nesse sentido primeiro devemos entender as origens científicas do conceito de 'raça', tendo este surgido no ocidente (assim com os conceitos de classe e nação) ainda no século XVIII, sendo primeiramente usado para qualificar "'[... a descendência comum de um conjunto de pessoas" (BANTON, 1977, p. 39). Já no século XIX ''[...] raça veio a significar uma qualidade física inerente' (idem, ibidem, p. 30).

Com o surgimento do cientificismo, no século XIX, vários pesquisadores europeus se interessaram em pesquisar sobre a categoria "raça" e seus desdobramentos, nesse segmento destacam-se pesquisas que categorizaram a espécie humana a partir de critérios biológicos e/ou culturais visando identificar e justificar: ' '[...] A existência das raças; [...] A continuidade entre o físico e o moral; [...] A ação do grupo sobre o indivíduo; a [...] Hierarquia universal dos valores; e a [...] Política baseada no saber" (TODOROV, 1939, p. 108 - 109 - 110), para essa doutrina científica deu-se o nome de racialismo. E é a partir da doutrina do racialismo que surge o comportamento conhecido como racismo (idem, ibidem, p. 107). .

O racismo, de sua gênese até o presente momento, está em constante transformação em todas as sociedades em que se faz presente. Ele tem origens no Ocidente, mais especificamente dentro dos processos de dominações coloniais, tendo sido tais processos endossados através de teorias racialistas (BANTON, 1977, p. 127). No Brasil, os conflitos, desigualdades e opressões pautadas em parâmetros raciais existem desde a chegada dos colonizadores europeus, porém, vale pontuarmos que ele vem passando por transformações, e, como consequência tornando-se cada vez mais complexo, institucionalizado e avançado, tudo em prol da manutenção de uma colonialidad del poder ${ }^{4}$ (QUIJANO, 2005).

\footnotetext{
${ }^{4}$ É o processo pautado por visões construídas na modernidade cuja a base eurocêntrica, capitalista e colonial delineia os padrões mundiais de poder e as perspectivas de produção de conhecimento.
} 
Aproximando o debate à nossa realidade, o racismo na América Latina, em destaque para a sociedade brasileira, se caracteriza pelo que Moore (2007, p. 278) classifica como '’[...] ordem pigmentocrática de dominação, fenotipofóbica, fenotipocêntrica e miscigenadora, geradora de preconceitos raciais e desigualdades sociais que são permanentemente negados ou escondidos"'. Posto isso, tais imbricações raciais são sustentadas por meio de instâncias ideológicas erigidas com a finalidade de ludibriar as relações sociais colocando grupos em condição de superioridade/inferioridade em detrimento de um suposto mito da "democracia racial".

Este mito que tanto marca a nossa sociedade é revestido pelo desejo consciente ou inconsciente de branquear a população através do processo de miscigenação. Nesse sentido, Abdias do Nascimento (2016) discorre que ele foi fundamentado no genocídio da população afrodescendente cujo objetivo principal era limitar o crescimento da população negra evitando sua reprodução. O autor, que é também referência na luta pelos direitos civis da população negra, acrescenta:

Para a solução deste grande problema - a ameaça da "mancha negra" - já vimos que um dos recursos utilizados foi o estupro da mulher negra pelos brancos da sociedade dominante, originando os produtos de sangue misto: o mulato, o pardo, o moreno, o parda-vasco, o homem-de-cor, o fusco, e assim por diante. O crime de violação e de subjugação sexual cometido contra a mulher negra pelo homem branco continuou como prática normal ao longo das gerações (NASCIMENTO, 2016, p.83).

Em resumo, o referido mito tem como fundamento principal pregar a imagem de que em uma nação miscigenada como a brasileira não há preconceito racial. Porém, Moore (2007, p. 263) é categórico ao afirmar que '’[... é pura ficção achar que a miscigenação reduz o racismo. Pelo contrário, ela o magnifica e o potencializa, tornando a vida nessas sociedades multirraciais um verdadeiro inferno"'. Vale pontuar que nos tempos em que vivemos, o racismo afeta todas as sociedades do mundo, nesse sentido Moore (2007) afirma que ele age na cultura, na política e até mesmo nas decisões militares (Idem, ibidem, 2007, p. 284).

\subsection{O racismo institucional: Sutil e perverso.}

O racismo institucional merece destaque na sociedade brasileira. Há registros históricos de sua presença neste país desde o século XIX, visto que durante a transição entre o trabalho escravo para o livre criaram-se mecanismos visando à manutenção do poder do grupo dominante (brancos) sobre grupos dominados (não brancos). Nesse cenário destacam-se a lei de terras (1850) e a lei da abolição (1888) pelo fato de ambas não terem prezado pela equidade entre as raças (LÓPEZ, 2012, p. 123). 
Nos dias atuais, constata-se que o racismo institucional está impregnado em todas as instituições brasileiras, seja no campo jurídico onde pessoas negras são maioria nos cárceres em função do tratamento desigual que recebem das instituições judiciais (SANTOS, 2013, p. 30), no campo da saúde onde o tratamento desigual entre pessoas brancas e pessoas negras tem gerado o aumento de doenças e mortalidade do último grupo (WERNECK, 2016, p. 540), ou na educação onde os próprios livros didáticos reproduzem o racismo através das representações imagéticas de pessoas negras causando constrangimento a estudantes da mesma raça (DA SILVA, 2013, p. 140).

Em nível de compreensão desta categoria cabe pontuar que o "racismo institucional"5, recrudesceu em meados da década de 1960 no contexto da luta por direitos civis, nos Estados Unidos - EUA. A grande distinção do racismo institucional para as outras formas de racismo estaria no fato de que, por este ter sido implantado nas regras de funcionamento das instituições, ele poderia se manifestar sem a vontade de quem o pratica, ou seja, um funcionário de um determinado órgão público poderia praticar racismo apenas por seguir os parâmetros de funcionamento do órgão no qual trabalha (SANTOS, 2013, p. 23).

Posto isso, o racismo institucional é identificado nas instituições e estruturas organizativas da sociedade e coloca pessoas ou grupos raciais ou étnicos em condição de desvantagem ou posição subalternizada. Souza (2011) chama a atenção desse conceito explicando que ele opera como instrumento que internaliza a produção das desigualdades sociais existentes em suas instituições. $\mathrm{O}$ autor acrescenta apontando a ligação que o racismo institucional tem com o processo de colonização ${ }^{6}$, pois a partir dele é criada sua base de sustentação e reprodução.

\begin{abstract}
A ideia é simples. Os aparatos institucionais de uma dada sociedade encontram-se a serviço dos grupos hegemônicos que os criam e fazem com que funcionem para a reprodução do sistema que lhe confere significado e existência. Alguém que esteja operando esse sistema poderá produzir resultados raciais injustamente diferenciados ainda que não tenha intenção de fazê-lo. Embora esse tipo de racismo possa ser de difícil detecção, suas manifestações são observáveis por meio dos padrões de sistemática desigualdade produzida pelas burocracias do sistema, que, por sua vez, ao lado das estruturas, formam as instituições (SOUZA, 2011, p. 80).
\end{abstract}

\footnotetext{
${ }^{5}$ O conceito de Racismo Institucional foi definido em 1967 pelos integrantes do grupo panteras negras Stokely Carmichael e Charles Hamilton, ambos ativistas.

${ }^{6}$ Hamilton e Ture (1992) afirmam que o racismo institucional é uma forma sutil que não pode ser associada somente aos atos dos indivíduos. Vai além disso e requer uma discussão e análise profunda acerca da influência do colonialismo nesse processo. Ler: HAMILTON, Charles and TURE, Kwame. Black Power - the politics of liberation in America. New York: Vintage Books, 1992.
} 
Como consequência, Santos (2013, p. 23) aponta que: 'Reconheceu-se que as instituições, práticas administrativas e estruturas políticas e sociais podiam agir de maneira adversa e racialmente discriminatória ou excludente". Nesse sentido, a busca por alterar as estruturas sociais existentes é condicionante para combater o racismo e conduzir as transformações necessárias no sistema excludente e segmentário no qual estamos inseridos. Isso implica também a conscientização de que indivíduos beneficiados no contexto de exclusão institucional podem não ter tido a intenção pessoal de discriminar, mas devem assumir, no mínimo, uma postura de comprometimento político e social com aqueles que não recebem as mesmas condições sociais favoráveis, sinalizadas pela ordem político/econômica global capitalista branca hegemônica e colonial.

Durante a execução de nossa pesquisa, enviamos ofícios para várias instituições de ensino situadas na cidade de Belém do Pará solicitando dados quantitativos a respeito da presença de estudantes caribenhos presentes em Belém do Pará, porém obtivemos retorno de apenas de uma instituição. Diante de tal situação fica o questionamento: A fata de interesse das referidas instituições em colaborar com nossa pesquisa seria uma forma de racismo institucional?

De modo geral, refletir sobre as instituições e o racismo nelas impregnado requer um esforço para tentar compreender as disputas em voga pelo poder, o que consequentemente formam as hierarquias e relações de subordinação. Nossa reflexão gira em torno da crítica a respeito de em que medida o Estado brasileiro atende às demandas institucionais de seus cidadãos negros e de suas cidadãs negras? E até que ponto o racismo presente na sua estrutura condiciona as relações sociais às negligências existentes no sistema? É possível superar essa questão? Ficam as reflexões.

\section{Apontamentos sobre a xenofobia}

A palavra xenofobia tem origem grega e surgiu a partir da articulação das palavras xénos (estranho, estrangeiro) e phobos (medo) por isso significa a rejeição, o preconceito em relação a quem se julga fora do meu lugar de origem, fora do meu território, ao diferente, ao estrangeiro. O medo e a rejeição a pessoas pertencentes a grupos distintos estão presentes na humanidade desde tempos remotos. Há registros de práticas xenófobas nas sociedades tribais (ALBUQUERQUE JUNIOR, 2016, p. 16), no mundo Grego (MOORE, 2007, p. 55) e até nas atuais sociedades modernas (ALBUQUERQUE JUNIOR, p. 61). 
A xenofobia se manifesta a partir do contato sensorial com o outro, ou seja, para o xenófobo um simples olhar, ouvir, cheirar ou tocar alguém estranho ao seu meio social pode lhe causar incômodo, aversão e até ódio (idem, ibidem, p, 169). Nessa ordem, na era vigente, as distinções que mais têm gerado comportamentos xenófobos são as marcadas por nacionalidade, religiosidade, ideologia política e raça, sendo o racismo bastante associado à xenofobia (idem, ibidem, p. 21).

Os sujeitos e as sujeitas que colaboraram com nossa pesquisa no Brasil são qualificados como "estrangeiros/as". Eles e elas, por não pertencerem ao solo em que se encontram, causam em algumas pessoas uma sensação de medo, desconfiança, insegurança por meio do seu próprio código cultural em contraste com o do/a outro/a, e tais sensações podem manifestar reações de diversas formas, seja violentando fisicamente, silenciando ou até mesmo se afastando deles/as. São as eliminações físicas e simbólicas do ser que é visto como "suspeito", o/a estrangeiro/a, ou seja, aquele que é "estranho a mim e aos meus", conforme aponta Simmel:

O estrangeiro por sua natureza não é proprietário do solo, e o solo não é somente compreendido no sentido físico, neste caso, mas, também, como uma substância delongada da vida, que não se fixa em um espaço específico, ou em um lugar ideal do perímetro social. Nas relações mais íntimas de pessoa a pessoa, também, todas as atrações e significâncias possíveis no cotidiano das experiências simbolizadas podem revelar o estrangeiro. O estrangeiro é sentido, então, precisamente, como um estranho, isto é, como um outro não "proprietário do solo". (SIMMEL, 1908, tradução KOURY, 2005 p. 266).

Através dessa pesquisa, pudemos ratificar o quanto o racismo e a xenofobia são elementos presentes nas vivências dos/as estudantes haitianos e percebemos o quanto são nocivos e cruéis na vida destes indivíduos, influenciando-os diretamente, sendo afetadas de forma negativa no que diz respeito às adaptações em outro país, as relações sociais e até mesmo o desempenho acadêmico obtido.

\subsection{A xenofobia e o racismo no Brasil: Opressões distintas, cor e alvo semelhantes}

No Brasil, o racismo e a xenofobia costumam caminhar juntos. Uma prova histórica que fundamenta tal afirmação sem tem ao comparar a receptividade de imigrantes oriundos da Europa e Ásia durante a segunda guerra mundial (1939-1945) com a receptividade dos Haitianos no contexto do início da década de 2010. Sobre esse último contexto citado, Cruz Neto (2017, p. 118) afirma que 'Xenofobia no Brasil tem cor e alvo'. A constituição 
brasileira em seu artigo $3^{\circ}$, inciso IV, afirma que "constituem objetivos fundamentais da República Federativa do Brasil promover o bem de todos, sem preconceitos de origem, raça, sexo, cor, idade e quaisquer outras formas de discriminação" (BRASIL, 1988).

Outro dado importante diz respeito ao artigo 140, parágrafo $3^{\circ}$, do Código Penal Brasileiro (1940) que trata do crime de injúria racial, sendo este agravado "se a injúria consiste na utilização de elementos referentes à raça, cor, etnia, religião, origem ou a condição de pessoa idosa ou portadora de deficiência" (BRASIL, 1940). Vale pontuar que quando ato xenófobo é praticado motivado pela cor de pele, no Brasil também se caracteriza como crime de racismo, de acordo com a Lei 7.716 (BRASIL, 1989).

Conforme mostramos, existem vários instrumentos na legislação brasileira que visam combater e punir o racismo e a xenofobia, contudo, na prática não se vê resultados, visto que as instituições jurídicas brasileiras não se interessam em investigar tais práticas às colocando como menos importante em relação a outros tipos de crimes (CRUZ NETO, 2017, p 51). Isso influencia bastante a não solução dessas questões relacionadas ao racismo e a xenofobia, justamente por não se dar prioridade nas pautas governamentais, afinal, para muitos o interesse é ínfimo, mas para outros chega a ser uma questão de sobrevivência.

O preconceito gerado pela xenofobia é algo bem complexo a ser analisado. Geralmente é manifestado através de ações discriminatórias que denotam ódio e intolerância aos indivíduos de outros países e de outras culturas. Alguns comportamentos podem gerar a violência quando as diferenças (e o não-respeito a elas) são postas e entram em choque. Nesse sentido, acreditamos que a xenofobia é um dos grandes problemas enfrentado na nossa sociedade e em outras consideradas mais "avançadas" e desenvolvidas economicamente. Até mesmo porque é necessário considerar não somente os níveis de desenvolvimento, mas as escalas de desigualdade encontradas. Em países multiétnicos e multiculturais, o contato com as diferenças provocadas pelos encontros da diversidade pode ocasionar a manifestação da xenofobia nesse contexto de pluralidade étnico-racial. Sendo assim, a xenofobia tende a ser uma manifestação dos distintos agrupamentos culturais humanos. Albuquerque Júnior conceitua:

A xenofobia, o medo e a rejeição ao estrangeiro, nasce, quase sempre, do estranhamento, da percepção da existência de uma estranheza, de uma hierarquia, de uma defasagem entre o que no ocidente chamamos de a humanidade de uns e de outros. Até mesmo do ponto de vista corporal, da imagem dos corpos, não é uma unanimidade o que seria um corpo humano, um corpo de humanos. A recusa e a aversão ao corpo do outro nasce, muitas vezes, do não reconhecimento da sua humanidade. Sempre que manifestamos o sentimento de xenofobia estamos 
atribuindo um certo déficit de humanidade ao outro, estamos pondo em questão seus direitos nascidos de sua pertença à nossa mesma espécie. Uma das mais básicas manifestações de xenofobia nasce da rejeição do corpo estranho, estrangeiro, do corpo exótico, bizarro, distinto que, em muitos casos extremados, sequer enxergamos como pertencentes à nossa espécie (ALBUQUERQUE JÚNIOR, 2016, p. 16).

O que gostaríamos de ressaltar neste artigo, não é a oposição ao estranhamento por si só - que, talvez, arriscamos a dizer ser natural - mas sim do estranhamento aos corpos fundamentados pela não partilha do mesmo habitat cultural e de socialização ao serem pensados como inferiores e de pouco prestígio. São essas delimitações hierárquicas provocadas pelo estranhamento que questionamos, a não humanidade em que os corpos "estrangeiros" (nessa perspectiva das diferenças) são pensados e tratados na nossa desigual sociedade, que inclusive, como já sabemos, é racista e xenófoba.

O fato é que tanto o racismo quanto a xenofobia são fenômenos nada novos e sempre atuais, e pode-se dizer que atuam na sociedade muitas vezes de forma interseccionada, subjugando sujeitos/as nas suas práticas de vivência cotidiana e influenciando na construção de relações de subordinação amparadas por uma ordem social desigual e excludente. Racismo e Xenofobia caminham juntos.

\section{Práticas de racismo e xenofobia contra universitários estrangeiros oriundos de países caribenhos em Belém do Pará.}

Apresentamos abaixo dois trechos de estudantes realizadas com um estudante haitiano e uma estudante jamaicana, respectivamente. Na época das entrevistas, eles se encontravam na cidade Belém do Pará por conta de estarem estudando na Universidade Federal do Pará - campus Guamá, com ingresso através dos programas de intercâmbio estudantil firmados pelos programas PEC $-\mathrm{G}^{7}$ (Programa estudante convênio - graduação) e PEC - PG8 (Programa estudante convênio - pós-graduação),

\footnotetext{
7 "A ideia da criação de um programa de governo para amparar estudantes de outros países adveio do incremento do número de estrangeiros no Brasil, na década de 1960, e das consequências que este fato trouxe para a regulamentação interna do status desses estudantes no Brasil. Havia necessidade de unificar as condições do intercâmbio estudantil e de garantir tratamento semelhante aos estudantes por parte das universidades. Dessa forma, em 1965 foi lançado o primeiro Protocolo do PEG - G. Desde 2013, o programa é regido pelo Decreto Presidencial n. 7. 948, que confere maior força jurídica ao regulamento do PEC-G. Atualmente, são 59 os países participantes no PEG-G, sendo 25 da África, 25 das Américas e nove da Ásia. Os cursos com o maior número de vagas oferecidas são Letras, Comunicação Social, Administração, Ciências Biológicas e Pedagogia. Desde os anos 2000, houve mais de 9.000 selecionados. A África é o continente de origem da maior parte dos estudantes com 76\% dos selecionados. Entre as nações africanas participantes, destacam-se Cabo Verde, Guiné Bissau e Angola"' (BRASIL, 2018).
}

'’O PEC-PG foi criado com o objetivo de possibilitar a cidadãos oriundos de países em desenvolvimento a realização de estudos de pós-graduação no Brasil, contribuindo, assim, para a formação de recursos humanos, 
ambos do governo Federal Brasileiro em parceria com governo de nações de todos os continentes do mundo. Por questões éticas os nomes dos entrevistados foram preservados, sendo eles denominados de "'estudante haitiano" e 'estudante jamaicana", respectivamente. Seguem os relatos:

Eu estava esperando um amigo próximo a um bloco salas de aula na Universidade Federal do Pará e havia uma senhora me olhando, e nem me cumprimentou, sendo que na minha educação temos que respeitar o mais velhos, esta senhora me perguntou: você é de onde? Eu respondi: sou do Haiti. Ela respondeu: o que você está fazendo aqui? Eu respondi: estou estudando. Ela respondeu: você recebe bolsa? Eu disse que sim. Aí ela começou a falar que não era pra eu estar aqui, pois não é pra isso que ela paga os impostos dela e que o governo deveria acabar com isso. Aí eu nem fiquei com raiva dela, pois alguns idosos costumam a falar coisas que não devem falar, entendeu? Aí eu só fiz ir embora. Na outra vez eu estava esperando passar o ônibus com um grupo de amigos e um senhor começou a falar: bando de macacos africanos vem pra cá roubar as vagas de nossos filhos nas Universidades. Aí eu fiquei um pouco constrangido, pois havia muita gente na parada de ônibus, mas nada fiz também. (Estudante Haitiano, 2017).

Um dia eu estava na fila do restaurante da Universidade Federal do Pará, aí havia uma mulher também na fila na minha frente. Tinha bastante gente na fila e em um dado momento involuntariamente eu encostei o meu corpo no dela. Em seguida pedi desculpas e permaneci calada. Depois disso eu notei que a mulher ficou nervosa e não parava de olhar para trás, ela até colocou a mochila dela para frente temendo que acontecesse algo. Como eu sou mais alta que ela de para notar que ela escreveu uma mensagem em seu celular dizendo '’amiga, tem uma negra estranha atrás de mim e estou com medo que ela me roube',. Após ler isso eu fiquei bastante constrangida, pois eu jamais faria isso. Também noto que quando estou no ônibus indo da Universidade para o local em que resido acompanhada de um colega de origem africana que tem o tom da pele mais escura que a minha as pessoas que estão no ônibus ficam olhando com estranheza para ele (Estudante Jamaicana, 2018).

nos moldes do PEC-G. O primeiro Protocolo foi assinado em 1981 e atualizado em 2006. Ao longo da última década, foram selecionados mais e 1.600 estudantes de pós-graduação. Cerca $75 \%$ das candidaturas vem de países das América, com destaque para Colômbia, Peru e Argentina. Os países africanos respondem por cerca de 20\% das candidaturas, com destaque para Moçambique, Cabo Verde e Angola. Entre os países asiáticos, responsáveis por cerca de 5\% das candidaturas, o Timor-Leste conta com maior número de inscritos e de selecionados. Atualmente, participam do PEC-PG 56 países, sendo 24 na África, 25 nas Américas e sete na Ásia. Na última edição do Programa, foram recebidas 596 candidaturas e concedidas 226 bolsas, distribuídas em 105 para mestrado e 121 para doutora', (BRASIL, 2018). 
No relato do estudante haitiano, nota-se que, apesar dele ser oriundo de uma nação que não pertence ao continente africano, por ser negro ele foi tratado de 'forma reducionista e homogênea como africano (MUNGOI, 2012, p. 127). Também fica evidenciada a presença de um "preconceito flagrante", (VALA; LIMA, 2004, p. 107), pautado no medo de uma suposta ameaça de desestabilização econômica provocada pela presença deste estudante haitiano em território brasileiro. Já no relato da estudante jamaicana, fica evidenciado manifestações preconceituosas mais sutis. Subuhana (2009, p. 121) justifica tais experiências pela ordem pigmentocrática vigente na sociedade brasileira. Segundo Vala\&Lima (2004, p.107), “o 'preconceito sutil', opera de maneira mais velada, manifestando-se através de olhares e/ou discursos onde o/s preconceito/s ficam implícitos entre o que foi dito e o que de fato se queria dizer".

Outra questão pertinente observada por nós diz respeito à socialização destes/as estudantes nos espaços acadêmicos da Universidade Federal do Pará, visto que eles/as costumam andar em grupos juntos com colegas estudantes oriundos/as de países do continente Africano, acentuando o distanciamento entre estudantes estrangeiros/as negros/as e estudantes brasileiros/as, conforme já evidenciado em outro contexto geográfico por De Souza Lima (2017, p. 04) e por Silva\&Morais (2012, p. 176).

A aliança entre esses/as estudantes estrangeiros/as é estabelecida desde a acolhida dos/as recém-chegados/as na cidade onde vão estudar, através de contato prévio com ao/as redes sociais de estudantes já estabelecidos/as na cidade até na sociabilidade, luta por direitos, lazer e compartilhamento de moradia (DE SOUZA LIMA, 2017, p. 05) (SILVA; MORAIS, 2012, p. 05). São através dessas redes que os/as participantes se blindam de opressões causadas pelo convívio em uma sociedade preconceituosa como a brasileira. No município de Belém do Pará a instituição responsável pelo fomento dessas práticas é a Associação de Estudantes Estrangeiros da Universidade Federal do Pará - AEE/UFPA.

\section{Conclusões}

Pudemos evidenciar com esta pesquisa que o racismo e a xenofobia operam no cotidiano das vivências de nossos/as interlocutores/as no município de Belém do Pará através de diversas facetas, sejam elas sutis ou gritantes. Todavia, tais práticas não impedem que estes/as estudantes sigam suas trajetórias na busca pelo sucesso de seus projetos de vida, e que estes/as também não vivenciem boas relações interpessoais no referido município, visto que eles/as possuem estratégias para isso, em destaque para o convívio solidário entre ele/as e os 
demais estudantes estrangeiros/as, proporcionado por suas redes sociais, e para as interações ocorridas no âmbito da Associação de estudantes estrangeiros da UFPA - AEE/UFPA.

De acordo com Moore (2007, p, 293) 'A luta permanente e multifacetada contra o racismo nas suas formas estruturais e sistêmicas, no imaginário social, e nas suas formulações ideológicas, se faz necessária em nível planetário’’. Já Albuquerque Junior (2016, p, 170) aponta que é somente através de práticas educativas que poderemos combater a xenofobia. Diante de tais afirmativas, nota-se que quanto mais aliados na luta a contra opressões motivadas por marcadores sociais da diferença (raça, classe, gênero, etc.), melhor.

Nesse sentido Ribeiro (2017, p.84) afirma que "é preciso cada vez mais que homens brancos cis estudem branquitude, cisgeneridade, masculinos", pois será somente com amplo apoio da sociedade brasileira que teremos eficácia no combate ao racismo e demais opressões. Seguindo essa perspectiva, convidamos outros/as pesquisadores/as a se interessarem em pelas temáticas do racismo e da xenofobia no Brasil, pois somente com amplos debates e práticas educativas iremos avançar no combate a tais opressões.

\section{Referências bibliográficas}

ALBUQUERQUE JÚNIOR, Durval Muniz. Xenofobia: Medo e Rejeição ao Estrangeiro. São Paulo: Cortez, 2016.

BAGGIO, Roberta Carmineiro; NASCIMENTO, Daniel Braga. Do Estatuto do Estrangeiro à nova Lei de Migração no Brasil: breves apontamentos. In: Migrações e direitos humanos: Problemática Sócioambiental, MÉJIA, Maria Rosa Gaviria (org). Ed: UNIVATES, 2018

BANTON, Michael. A ideia de raça. 1979.

BRASIL. Histórico do programa estudante convenio graduação - PEC-G. Disponível em: http://www.dce.mre.gov.br/PEC/G/historico/introducao.php. Acesso em: 15/09/2018.

. Histórico do programa estudante convenio pós-graduação - PEC-PG. Disponível em: http://www.dce.mre.gov.br/PEC/PG/historico.html. Acesso em: 15/09/2018.

CABECINHAS, Rosa. Racismo e xenofobia: a actualidade de uma velha questão. Comunicación e Cidadanía. n.2 2008 (p.163-181).

CRUZ NETO, Reinaldo Venâncio da. No Brasil, xenofobia tem cor e alvo: a realidade do deslocamento humano de haitianos ao Brasil, através do Estado do Acre, pós-catástrofe natural no Haiti em 2010. 2017. 135 f., il. Dissertação (Mestrado em Direito)—Universidade de Brasília, Brasília, 2017. 
DA EDUCAÇÃO SUPERIOR, INEP Censo. Divulgação dos Principais Resultados. Instituto Nacional de Estudos e Pesquisas Educacionais Anísio Teixeira (INEP). Ministério da Educação (MEC), 2016.

DA SILVA, Paulo Vinicius Baptista; TEIXEIRA, Rozana; PACIFICO, Tânia Mara. Políticas de promoção de igualdade racial e programas de distribuição de livros didáticos. Revista Educação e Pesquisa, v. 39, n. 1, p. 127-143, 2013.

DE MELO ROSA, Renata; DE MORAIS ALCÂNTARA, Pedro Ivo. Em busca do visto prometido: uma análise da política migratória brasileira e as aspirações da população haitiana migrante em Porto Velho/RO 10.5102/uri. v12i2. 3196. Revista Universitas: Relações Internacionais, v. 12, n. 2, 2015.

DE SOUZA, Arivaldo Santos. Racismo Institucional: para compreender o conceito. Revista da Associação Brasileira de Pesquisadores/as Negros/as (ABPN), v. 1, n. 3, p. 77-88, 2011.

DE SOUSA LIMA, Luciana; FEITOSA, Giulliany Gonçalves. Sair da África para estudar no Brasil: fluxos em discussão. Revista Psicologia \& Sociedade, v. 29, 2017.

DUARTE, Rosália. Pesquisa qualitativa: reflexões sobre o trabalho de campo. Cadernos de pesquisa, n. 115, p. 139-154, 2002.

TODOROV, Tzvetan.. Nós e os outros: a reflexão francesa sobre a diversidade humana. Jorge Zahar: Rio de Janeiro, 1993.

HIRSCH, Olivia Nogueira. "A gente parece um camaleão: (re)construções identitárias em um grupo de estudantes cabo-verdianos no Rio de Janeiro. Pro-Posições, v.20, n.1. Campinas, 2009 (p.65-81).

LÓPEZ, Laura Cecilia. O conceito de racismo institucional: aplicações no campo da saúde. Interface-Comunicação, Saúde, Educação, v. 16, p. 121-134, 2012.

LIMA, Marcus Eugênio Oliveira; VALA, Jorge. As novas formas de expressão do preconceito e do racismo. Estudos de psicologia (Natal), 2004.

MOORE, Carlos W. Racismo \& Sociedade: novas bases epistemológicas para entender o racismo. Mazza, 2007.

MUNGOI, Dulce Maria Domingos Chale João. Ressignificando identidades: um estudo antropológico sobre experiências migratórias dos estudantes africanos no Brasil. Revista Interdisciplinar da Mobilidade Humana, v. 20, n. 38, 2012.

NASCIMENTO, Abdias. $O$ genocídio do negro brasileiro: processo de um racismo mascarado. Editora Perspectiva SA, 2016.

PAULA, Elder Andrade de. Entre desastres e transgressões, a chegada dos imigrantes haitianos no "reino deste mundo amazônico". Novos Cadernos NAEA, v. 16, n. 2, 2013 (p.187-206).

PISCITELLI, A. G. Tradição oral, memória e gênio: um comentário metodológico. In: Cadernos Pagu. Trajetórias e sentimentos. Campinas, IFCH/UNICAMP, n.1, 1993. Brasil e no Rio Grande do Sul. Tempo da Ciência, v. 23, n. 46, p. 115-131.

Quijano, Aníbal. "Colonialidad del poder, eurocentrismo y América Latina.(2000)." Edgardo Lander (comp.) La colonialidad del saber: eurocentrismo y ciencias sociales. Perspectivas 
Latinoamericanas. Buenos Aires, Argentina: CLACSO, Consejo Latinoamericano de Ciencias Sociales: 201-246.2005.

RIBEIRO, Djamilla. O que é lugar de fala? Justificando, 2017.

ROCHA-TRINDADE, M. B. Sociologia das migrações. Lisboa: Universidade Aberta, 1995.

SANTOS, Ivair Augusto Alves dos. Direitos humanos e as práticas de racismo. In: Direitos humanos e as práticas de racismo. 2013.

SIMMEL, Georg. Soziologie. Untersuchungen über die Formen der Vergesellschaftung (Sociologia. Estudos sobre as formas de sociação). Berlim, Duncker e Humblot Editores, 1908, pp. 509 a 512. Tradução de Mauro Guilherme Pinheiro KOURY, 2005.

SILVA, Kelly; MORAIS, Sara Santos. Tendências e tensões de sociabilidade de estudantes dos Palop em duas universidades brasileiras. Pro-Posições, v. 23, n. 1, p. 163-182, 2012.

SOUZA, Arivaldo Santos de. Racismo Institucional: para compreender o conceito. Revista da Associação Brasileira de Pesquisadores/as Negros/as (ABPN), v. 1, n. 3, 2011 (p. 77-88).

SUBUHANA, Carlos et al. A experiência sociocultural de universitários da África Lusófona no Brasil: entremeando histórias. Pro-Posições, v. 20, n. 1, p. 103-126, 2009.

THOMAZ, Omar Ribeiro. Eles são assim: racismo e o terremoto de 12 de janeiro de 2010 no Haiti. Cadernos de Campo (São Paulo, 1991), v. 20, n. 20, 2011 (p. 273-284).

WERNECK, Jurema. Racismo institucional e saúde da população negra. Saúde e Sociedade, v. 25, p. 535-549, 2016.

VALENCIO, N. Da morte da qimera à procura de Pégaso: a importância da interpretação sociológica na análise do fenômeno chamado desastre. In: VALENCIO, N. et al. (Orgs.). Sociologia dos desastres. Construção, interfaces e perspectivas no Brasil. São Carlos: Rima, 2009.

VÉRAN, Jean-François; DA SILVA NOAL, Débora; FAINSTAT, Tyler. Nem refugiados, nem migrantes: a chegada dos haitianos à cidade de Tabatinga (Amazonas). Revista de Ciências Sociais, v. 57, n. 4, 2014. 